\title{
Transformerless Three-Level DC-DC Buck Converter with a High Step-Down Conversion Ratio
}

\author{
Yun Zhang ${ }^{\dagger}$, Xing-tao Sun ${ }^{* *}$, Yi-feng Wang ${ }^{*}$, and Hong-jun Shao* \\ ${ }^{\dagger *}$ School of Electrical Engineering and Automation, Tianjin University, Tianjin, China \\ ${ }^{* *}$ School of Electrical Engineering and Automation, Tianjin Polytechnic University, Tianjin, China
}

\begin{abstract}
For high power high step-down dc-dc conversion applications, conventional three-level dc-dc converters are subject to extreme duty cycles or increased volume and cost due to the use of transformers. In this paper, a transformerless three-level dc-dc buck converter with a high step-down conversion ratio is proposed. The converter comprises two asymmetrical half bridges, which are of the neutral point clamped structures. Therefore, the output pulse voltage of the converter can be obtained in terms of the voltage difference between the two half bridges. In order to realize harmonious switching of the converter, a modulation strategy with capacitor voltages self balance is presented. According to the deduced output de voltage function, transformerless operation without extreme duty cycles can be implemented. Experimental results from a $1 \mathrm{~kW}$ prototype verify the validity of the proposed converter. It is suitable for ship electric power distribution systems.
\end{abstract}

Key words: DC-DC buck converter, High step-down conversion, Non-extreme duty cycles, Three-level

\section{INTRODUCTION}

With the development of power electronics techniques, there has been a growing interest in multilevel converters for high power and high voltage applications [1]-[6]. Basically, there are three types of multilevel inverters for dc-ac applications: diode-clamped inverters, flying-capacitor inverters, and cascaded H-bridge inverters [7]-[9]. In 1981, the neutral point clamped (NPC) three-level inverter was proposed by A. Nabae [10]. During the following years, this concept for a multilevel conversion technique has been applied to dc-dc applications. J. R. Pinheiro proposed a three-level ZVS (zero-voltage switching) PWM converter with the NPC structure in 1992 [11]. Then a new concept in high voltage dc-dc conversion was established.

Later, the basic family of three-level dc-dc converters was discussed in [12]. From the conventional half bridge converter, the half bridge three-level converter was derived with the so-called three-level switch cells. Then, six nonisolated three-level converters based on the buck, boost,

Manuscript received Dec. 11, 2011; revised Nov. 21, 2012

Recommended for publication by Associate Editor Hanju Cha.

†Corresponding Author: zhangy@tju.edu.cn

Tel: +86-013-0322-1076, Tianjin University

*School of Electrical Eng. and Automation, Tianjin University, China

${ }^{* *}$ School of Electrical Eng. and Automation, Tianjin Polytechnic University, China buck-boost, Cuk, SEPIC, and Zeta topologies were obtained, as well as five isolated three-level converters based on the forward, flyback, push-pull, half bridge, and full bridge topologies.

As for three-level step-down converters, the non-isolated three-level dc-dc buck converter is the basic topology to implement the conversion from a high voltage input to a low voltage output. Unfortunately, this basic topology may also be subject to extreme duty cycles when a high step-down conversion is required [13]. Therefore, the output rectifier diode in the basic three-level buck converter must sustain a short pulse width current with a high amplitude, which leads to severe reverse recovery and high electromagnetic interference (EMI) problems [14], [15]. Moreover, extreme duty cycles are not desirable, because no space is left for the controller to compensate changes in load or line.

Another solution to achieve a high step-down voltage gain is to increase the turns ratio of the transformer. Such an isolated three-level dc-dc converter can deal with the input high voltage and avoid the extreme duty cycles due to the presence of a transformer. Although the circulating current can be minimized effectively, the transformer design is critical to the success of the converter performance [16]. However, several applications require high step-down non-isolated dc-dc converters, for example, the buck type PFC (power factor correction) [17], the buck converter used 
in ship electric power distribution systems [16], and so on. A transformerless dc-dc converter without extreme duty cycles is necessary to decrease the volume and to increase efficiency.

In this paper, a transformerless three-level dc-dc buck converter with a high step-down conversion ratio is proposed for ship electric power distribution systems. This converter can convert a high DC bus voltage to a low DC voltage for important DC loads of high power. In Section II, the circuit of the converter is presented and the operation principles are described in detail. Then a modulation strategy which can satisfy the operation of the converter is proposed with the capacitor voltages self balance, and the function of the output dc voltage $V_{\mathrm{o}}$ is deduced. Moreover, the principle of transformerless operation without extreme duty cycles is also clarified when the step-down conversion ratio is rather high. In Section III, a $1 \mathrm{~kW}$ hardware prototype for the resistive load has been designed and tested to verify the validity of the converter operation and performance.

\section{OPERATIONAL PRINCIPLES OF THE PROPOSED CONVERTER}

\section{A. Topology and Operation of the Converter}

Fig. 1 shows the proposed transformerless three-level dc-dc buck converter with a high step-down conversion ratio. $V_{\text {in }}$ is the input de voltage. The input filtering capacitors $C_{1}$ and $C_{2}$ are series connected and serve as a capacitive voltage divider to split the input dc voltage $V_{\text {in }}$ into two equal voltages $V_{\mathrm{C} 1}$ and $V_{\mathrm{C} 2}$. Then there are three voltage levels: zero, $V_{\text {in }} / 2$ and $V_{\text {in }}$. The converter comprises the left half bridge (LHB) "a" and the right half bridge (RHB) "b". The LHB "a" consists of the power switches $\mathrm{Q}_{1}$ and $\mathrm{Q}_{2}$, and the diodes $\mathrm{D}_{1}$ and $\mathrm{D}_{2}$, whose blocking voltages are all clamped at $V_{\text {in }} / 2$ via the clamped diodes $\mathrm{D}_{\mathrm{c} 1}$ and $\mathrm{D}_{\mathrm{c} 2}$. The RHB " $\mathrm{b}$ " consists of the power switches $\mathrm{Q}_{3}$ and $\mathrm{Q}_{4}$, and the diodes $\mathrm{D}_{3}$ and $\mathrm{D}_{4}$, whose blocking voltages are also clamped at $V_{\text {in }} / 2$ via the clamped diodes $\mathrm{D}_{\mathrm{c} 3}$ and $\mathrm{D}_{\mathrm{c} 4}$. Finally, the output dc voltage $V_{\mathrm{o}}$ is obtained by the filters $\left(L_{\mathrm{f}}\right.$ and $\left.C_{\mathrm{f}}\right)$ between the output ports "a" and "b" of the converter for supplying power to the load $R$, as shown in Fig. 1 .

Both the LHB and the RHB can operate, and the switching state concept is introduced in this paper, namely $\mathrm{S}_{x}=$ "0" or "1" denotes that $\mathrm{Q}_{x}$ is off or on $(x=1 \sim 4)$. As for the LHB, the three-level output voltage $V_{\text {ag }}$ is $V_{\text {in }}$ when the switching state is $\mathrm{S}_{1} \mathrm{~S}_{2}=11$. If the switching state is $\mathrm{S}_{1} \mathrm{~S}_{2}=01, V_{\text {ag }}$ is $V_{\text {in }} / 2$, which is the voltage across $\mathrm{C}_{2}$, and the voltage stress of $\mathrm{Q}_{1}$ is $V_{\text {in }} / 2$ (the voltage across $\mathrm{C}_{1}$ ). $V_{\text {ag }}$ becomes zero when the switching state is $\mathrm{S}_{1} \mathrm{~S}_{2}=00$. Meanwhile, $\mathrm{D}_{1}$ and $\mathrm{D}_{2}$ are freewheeling, and $\mathrm{Q}_{1}$ and $\mathrm{Q}_{2}$ are both clamped by the voltages $\left(V_{\mathrm{in}} / 2\right)$ across $\mathrm{C}_{1}$ and $\mathrm{C}_{2}$, respectively.

As for the RHB, the three-level output voltage $V_{\mathrm{bg}}$ is zero when the switching state is $\mathrm{S}_{3} \mathrm{~S}_{4}=11$. When the switching state is $\mathrm{S}_{3} \mathrm{~S}_{4}=10, V_{\text {bg }}$ is $V_{\text {in }} / 2$ (the voltage across $\mathrm{C}_{2}$ ), and the

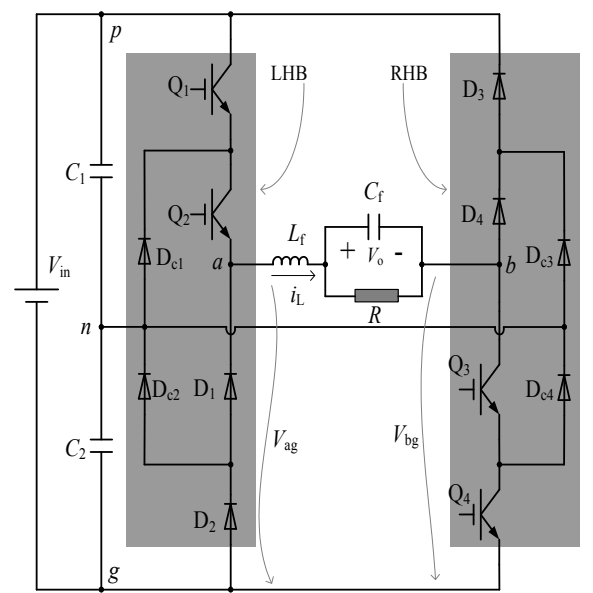

Fig. 1. Circuit diagram of the proposed converter.

blocking voltage of $\mathrm{Q}_{4}$ is the voltage across $\mathrm{C}_{2} . V_{\mathrm{bg}}$ is $V_{\text {in }}$ when the switching state is $\mathrm{S}_{3} \mathrm{~S}_{4}=00$, and $\mathrm{D}_{3}$ and $\mathrm{D}_{4}$ are freewheeling. At the same time, the blocking voltages of $\mathrm{Q}_{3}$ and $\mathrm{Q}_{4}$ are across $\mathrm{C}_{1}$ and $\mathrm{C}_{2}$, respectively. As a result, the output pulse voltage $\left(V_{\mathrm{ab}}\right)$ between the output ports "a" and "b" of the proposed converter can be obtained as follows:

$$
V_{\mathrm{ab}}=V_{\mathrm{ag}}-V_{\mathrm{bg}}
$$

According to (1), the available pulse voltage $V_{\mathrm{ab}}$ can be generated in the case of harmonious switching of the four power switches $\mathrm{Q}_{1} \sim \mathrm{Q}_{4}$, namely the switching state " $\mathrm{S}_{1} \mathrm{~S}_{2} \mathrm{~S}_{3} \mathrm{~S}_{4}$." Assuming that the inductor current $i_{\mathrm{L}}$ is continuous, there are six operation modes of the proposed converter, as shown in Fig. 2. When the switching state is $\mathrm{S}_{1} \mathrm{~S}_{2} \mathrm{~S}_{3} \mathrm{~S}_{4}=0110, i_{\mathrm{L}}$ flows through: $\mathrm{Q}_{2}$, the filter and the load $\left(L_{\mathrm{f}}\right.$ $C_{\mathrm{f}}$ and $\left.R\right), \mathrm{Q}_{3}$, and the clamped diodes $\mathrm{D}_{\mathrm{c} 4}$ and $\mathrm{D}_{\mathrm{c} 1}$, as shown in Fig. 2(a). Then the pulse voltage $V_{\mathrm{ab}}$ is zero. When $i_{\mathrm{L}}$ flows through the filter and load, the power switches $\mathrm{Q}_{3}$ and $\mathrm{Q}_{4}$, and diodes $\mathrm{D}_{2}$ and $\mathrm{D}_{1}$, as shown in Fig. 2(b), $V_{\mathrm{ab}}$ is also zero. Under similar condition to Fig. 2(b), as shown in Fig. 2(c), $i_{\mathrm{L}}$ flows through the filter and load, diodes $\mathrm{D}_{4}$ and $\mathrm{D}_{1}$, and the power switches $\mathrm{Q}_{1}$ and $\mathrm{Q}_{2}$. Consequently, $V_{\mathrm{ab}}$ is zero all the same. The operation modes in Figs. 2(a) (c) are all in freewheeling states due to the continuous inductor current $i_{\mathrm{L}}$. Namely, the converter has three redundant states for $V_{\mathrm{ab}}=0$.

When the switching state is $\mathrm{S}_{1} \mathrm{~S}_{2} \mathrm{~S}_{3} \mathrm{~S}_{4}=0111$, as shown in Fig. 2(d), the inductor current $i_{\mathrm{L}}$ flows through the filter and the load, the power switches $\mathrm{Q}_{3}$ and $\mathrm{Q}_{4}$, the filtering bottom capacitor $\mathrm{C}_{2}$, the clamped diode $\mathrm{D}_{\mathrm{cl}}$ and the power switch $\mathrm{Q}_{2}$. Then $V_{\mathrm{ab}}=V_{\text {in }} / 2$ can be obtained due to the voltage across the bottom divided capacitor $\mathrm{C}_{2}$. As a result, $\mathrm{C}_{2}$ is discharged to supply the energy for the load $R$.

In addition, $V_{\mathrm{ab}}=V_{\text {in }} / 2$ can be generated when the switching state is $\mathrm{S}_{1} \mathrm{~S}_{2} \mathrm{~S}_{3} \mathrm{~S}_{4}=1110$, as shown in Fig. 2(e). Then, the inductor current $i_{\mathrm{L}}$ flows through the filter and the load, the power switch $\mathrm{Q}_{3}$, the clamped diode $\mathrm{D}_{\mathrm{cl}}$, the filtering upper capacitor $\mathrm{C}_{1}$, and the power switches $\mathrm{Q}_{1}$ and $\mathrm{Q}_{2}$. Therefore, the upper divided capacitor $\mathrm{C}_{1}$ is also discharged, taking the 


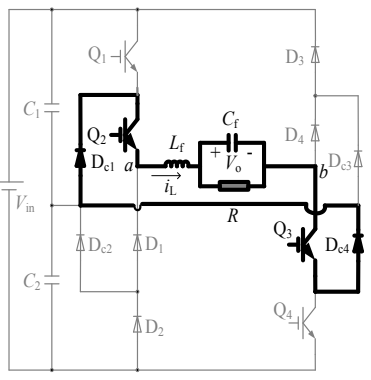

(a) $\mathrm{S}_{1} \mathrm{~S}_{2} \mathrm{~S}_{3} \mathrm{~S}_{4}=0110, V_{\mathrm{ab}}=0$.

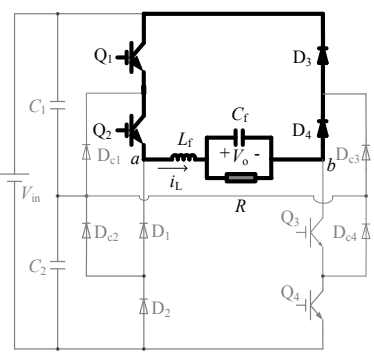

(c) $\mathrm{S}_{1} \mathrm{~S}_{2} \mathrm{~S}_{3} \mathrm{~S}_{4}=1100, V_{\mathrm{ab}}=0$.

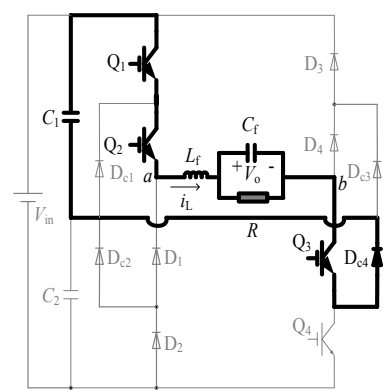

(e) $\mathrm{S}_{1} \mathrm{~S}_{2} \mathrm{~S}_{3} \mathrm{~S}_{4}=1110, V_{\text {ab }}=V_{\text {in }} / 2$.

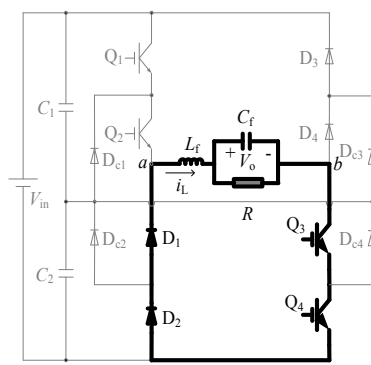

(b) $\mathrm{S}_{1} \mathrm{~S}_{2} \mathrm{~S}_{3} \mathrm{~S}_{4}=0011, V_{\mathrm{ab}}=0$.

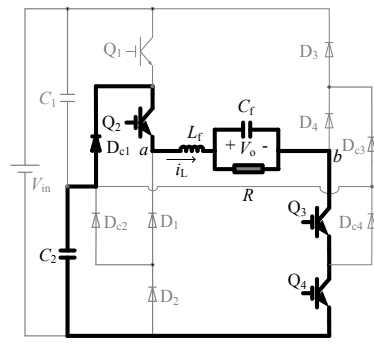

(d) $\mathrm{S}_{1} \mathrm{~S}_{2} \mathrm{~S}_{3} \mathrm{~S}_{4}=0111, V_{\mathrm{ab}}=V_{\text {in }} / 2$.

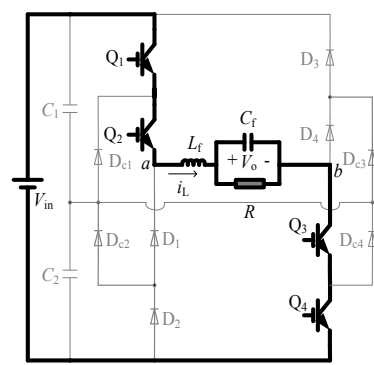

(f) $\mathrm{S}_{1} \mathrm{~S}_{2} \mathrm{~S}_{3} \mathrm{~S}_{4}=1111, V_{\mathrm{ab}}=V_{\text {in. }}$

Fig. 2. Topological operation modes of the proposed converter.

power supply for the load $R$. Namely, there is the another redundant switching state for $V_{\mathrm{ab}}=V_{\mathrm{in}} / 2$.

The last operation mode, as shown in Fig. 2(f), can be realized when the switching state is $\mathrm{S}_{1} \mathrm{~S}_{2} \mathrm{~S}_{3} \mathrm{~S}_{4}=1111$. Then, the inductor current $i_{\mathrm{L}}$ flows through the filter and the load, the RHB power switches $\mathrm{Q}_{3}$ and $\mathrm{Q}_{4}$, the input de power supply $V_{\text {in }}$, and the LHB power switches $\mathrm{Q}_{1}$ and $\mathrm{Q}_{2}$. Hence the pulse voltage $V_{\text {ab }}$ becomes $V_{\text {in }}$.

\section{B. Modulation Strategy with Capacitor Voltages Self Balance}

In order to carry out harmonious switching of the converter's power switches and to achieve a high voltage gain, the key modulation strategy is proposed in Fig. 3, based on the principle of the proposed converter. The modulation indices of the left and right half bridges are $m_{\mathrm{a}}$ and $m_{\mathrm{b}}$, respectively, as shown in Fig. 3(a). Both carrier waves (carrier1 and carrier2) are $\pi$ phase-shifted. In every carrier period $(T)$, the modulation law is designed as follows:

$$
\left\{\begin{array}{l}
m_{\mathrm{b}}>V_{\text {carrier } 1}, \mathrm{~S}_{1}=0 \\
m_{\mathrm{a}}>V_{\text {carrier } 2}, \mathrm{~S}_{2}=1 \\
m_{\mathrm{a}}>V_{\text {carrier } 1}, \mathrm{~S}_{3}=1 \\
m_{\mathrm{b}}>V_{\text {carrier } 2}, \mathrm{~S}_{4}=0
\end{array}\right.
$$

where $V_{\text {carrier1 }}$ and $V_{\text {carrier2 }}$ are the instantaneous values of carrier1 and carrier2, respectively.

By virtue of (2), the gate signals of the four power switches $\mathrm{S}_{1} \sim \mathrm{S}_{4}$ (as well as the switching states) are shown in Figs. 3(b) (e) and (h). Then, the output three-level voltages are generated by each half bridge, as shown in Figs. 3(f) and (g). Taking advantage of (1), the pulse voltage $V_{\mathrm{ab}}$ can be shown in Fig. 3(h). There are five switching states $\left(\mathrm{S}_{1} \mathrm{~S}_{2} \mathrm{~S}_{3} \mathrm{~S}_{4}\right)$ in the first half period $(0 \sim T / 2)$ due to redundant switching states. In order these switching states are: 0110-1110-1100-1110-0110 (as shown in Fig. 3(h)). Then, the two voltage pulses of $V_{\mathrm{ab}}$ $\left(V_{\text {in }} / 2\right)$ can be obtained between the output ports "a" and "b" just when the switching state is "1110," as shown in Fig. 3(h). This results in the discharging of the upper divided capacitor $\mathrm{C}_{1}$ for the load, as shown in Fig. 3(j). Similarly, in the second half period $(T / 2 \sim T)$, the corresponding five switching states are in order: 0110-0111-0011-0111-0110. Then, the other two voltage pulses of $V_{\mathrm{ab}}\left(V_{\mathrm{in}} / 2\right)$ are obtained due to the switching state "0111," as shown in Fig. 3(h). As a result, the load is supplied by the bottom divided capacitor $\mathrm{C}_{2}$, and $\mathrm{C}_{2}$ is discharged, as shown in Fig. 3(k).

It is worth noting that there is only one switching change between the adjacent switching states, as depicted in Fig. 3(h). Consequently, the requirement of minimal switching losses can be met freely. According to the analysis of the topological operation modes, when $V_{\mathrm{ab}}=V_{\mathrm{in}} / 2$, both $\mathrm{C}_{1}$ and $\mathrm{C}_{2}$ are charged and discharged in turn in every carrier period, as shown in Figs. 3(j) and (k). The modulation waves $m_{\mathrm{a}}$ and $m_{\mathrm{b}}$ and the average inductor current $I_{\mathrm{L}}$ can all be considered constant in every carrier period. In addition, the carriers are symmetrical, so the discharging/charging time of $\mathrm{C}_{1}$ and $\mathrm{C}_{2}$ can be equal, namely $t_{1 \_}=t_{2 \_}$, as shown in Figs. 3(c) and (d). Therefore, the voltages $\left(V_{\mathrm{C} 1}\right.$ and $\left.V_{\mathrm{C} 2}\right)$ across $\mathrm{C}_{1}$ and $\mathrm{C}_{2}$ can be self balanced in each carrier period. Furthermore, the equivalent frequency of $V_{\mathrm{ab}}$ is double the switching frequency, as shown in Figs. 3(a) and (h).

Assuming that the inductor current $i_{\mathrm{L}}$ is continuous, the energy $W_{\text {st }}$ is stored by $L_{\mathrm{f}}$ when $V_{\mathrm{ab}}$ is $V_{\text {in }} / 2$. This leads to $i_{\mathrm{L}}$ increasing linearly, as shown in Fig. 3(i). The energy $W_{\text {tr }}$ is transferred when $V_{\mathrm{ab}}$ is 0 , and it results in $i_{\mathrm{L}}$ decreasing linearly, as shown in Fig. 3(i). In every carrier period, $W_{\text {st }}$ and $W_{\text {tr }}$ can be described as follows:

$$
\left\{\begin{array}{l}
W_{\mathrm{st}}=\left(V_{\mathrm{in}} / 2-V_{\mathrm{o}}\right) \times I_{\mathrm{L}} \times 2 \times\left(t_{\mathrm{on} 1}-t_{\mathrm{off} 3}\right) \\
W_{\mathrm{tr}}=V_{\mathrm{o}} \times I_{\mathrm{L}} \times\left[T-2 \times\left(t_{\mathrm{on} 1}-t_{\mathrm{off} 3}\right)\right] \\
W_{\mathrm{st}}=W_{\mathrm{tr}}
\end{array}\right.
$$




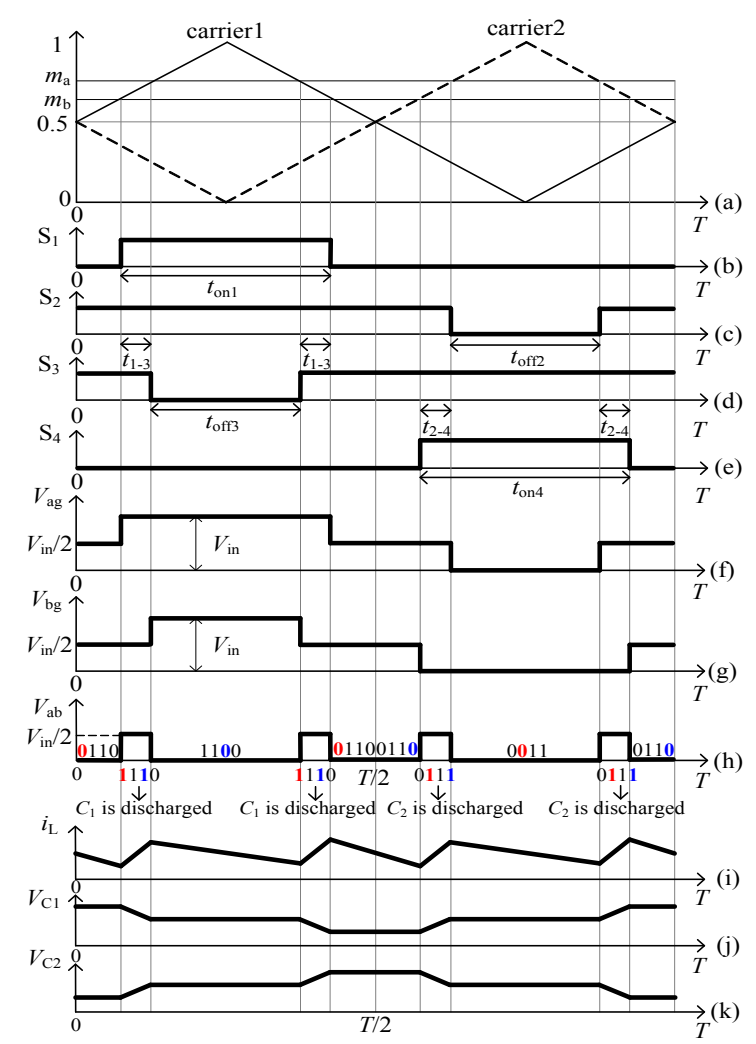

Fig. 3. Modulation strategy with capacitor voltages self balance.

where $V_{\mathrm{o}}$ is the output dc voltage after the $L_{\mathrm{f}} C_{\mathrm{f}}$ filter, $t_{\mathrm{on} 1}$ is the gate-on time of the power switch $\mathrm{Q}_{1}$, and $t_{\text {off3 }}$ is the gate-off time of the power switch $\mathrm{Q}_{3}$, as shown in Fig. 3. From Figs. 3(a) (e), the corresponding duty cycles $d_{1} \sim d_{4}$ of the four power switches $Q_{1} \sim Q_{4}$ are described as:

$$
\left\{\begin{array}{l}
d_{1}=d_{4}=\frac{t_{\mathrm{on} 1}}{T}=1-m_{b} \\
d_{3}=d_{2}=\frac{T-t_{\mathrm{off} 3}}{T}=m_{a}
\end{array}\right.
$$

By combining (3) and (4), $V_{\mathrm{o}}$ can be written as:

$$
V_{\mathrm{o}}=V_{\text {in }} \times\left(m_{\mathrm{a}}-m_{\mathrm{b}}\right)
$$

Namely, $V_{\mathrm{o}}=V_{\text {in }} \times\left(d_{1}+d_{2}-1\right)$ can be obtained and the limited conditions are $0 \leq m_{\mathrm{b}}<m_{\mathrm{a}} \leq 1$ and $m_{\mathrm{a}}+m_{\mathrm{b}}>1$.

\section{Transformerless Operation without Extreme Duty Cycles}

For conventional three-level dc-dc buck converters without transformers, a high step-down conversion may always be achieved by means of extreme duty cycles. For example, when the voltage gain is higher, $10\left(V_{\mathrm{in}} / V_{\mathrm{o}}\right)$, the conventional duty cycle may be $\mathbf{0 . 1}$, which is far from $\mathbf{0 . 5}$. Fortunately, the duty cycles of the proposed transformerless scheme may be 0.6 and 0.5 by setting $m_{\mathrm{a}}=0.6$ and $m_{\mathrm{b}}=0.5$, by virtue of (4) and (5).

In fact, the essence of transformerless operation without extreme duty cycles is that the output pulse voltage $V_{\mathrm{ab}}$ is obtained from the three-level voltage difference between $V_{\mathrm{ag}}$ and $V_{\text {bg }}$, by means of Figs. 3(f) (h). The short pulse width is up to the switching time intervals $t_{13}$ and $t_{24}$, as shown in Figs. 3(d) and (e), which can be described as:

$$
\left\{\begin{array}{l}
t_{1 \_3}=\frac{t_{\text {on } 1}-t_{\text {off } 3}}{2} \\
t_{2_{-} 4}=\frac{t_{\text {on } 4}-t_{\text {off } 2}}{2}
\end{array}\right.
$$

and $t_{1 \_3}=t_{2 \_}$can be confirmed due to the symmetrical geometry relationships in Fig. 3. According to (4) (6), an identical voltage gain has infinite solution sets for $m_{\mathrm{a}}$ and $m_{\mathrm{b}}$. As a result, with a higher step-down conversion ratio, optimum duty cycles can be chosen for the transformerless operation of the proposed converter, instead of the extreme ones. The simple selection method for $m_{\mathrm{a}}$ and $m_{\mathrm{b}}$ is to first set $m_{\mathrm{b}}$ as a constant, for example, 0.55 in this paper, according to the tradeoff between the duty cycles $\left(d_{1}\right.$ and $\left.d_{4}\right)$ which are near 0.5 , and the fluctuating amplitude of the inductor current. Then $m_{\mathrm{a}}$ can be obtained by means of the output $\left(m_{\mathrm{a}}-m_{\mathrm{b}}\right)$ of the current PI controller.

\section{Filter Design of the Converter}

The filter of the proposed converter is important in terms of its operation performance, and it includes the filtering inductor $L_{\mathrm{f}}$, and the filtering capacitor $C_{\mathrm{f}}$. Therefore, the minimum values of $L_{\mathrm{f}}$ and $C_{\mathrm{f}}$ can be obtained according to the required maximum inductor current ripple $\Delta I_{\mathrm{L}_{-} \max }$ and the output voltage ripple $\Delta V_{\text {o_max }}$, respectively. According to (3) and Fig. 3 , when $V_{\mathrm{ab}}$ is zero the energy stored in $L_{\mathrm{f}}$ is transferred, which leads to the filtering inductor current falling. As a result, the longer the falling time, the larger the inductor current ripple becomes.

In this paper, the longer falling time $t_{\mathrm{f}}$ is $t_{\mathrm{off} 2}$ or $t_{\mathrm{off} 3}$, as shown in Figs.3 (c) and (d). Then $t_{\mathrm{f}}$ can be obtained as:

$$
t_{\mathrm{f}}=\left(1-d_{2}\right) \cdot T
$$

where $T$ is the carrier period. During $t_{\mathrm{f}}$, the voltage of $L_{\mathrm{f}}$ is written as:

$$
u_{\mathrm{L}}=0-V_{\mathrm{o}}=-\left(d_{1}+d_{2}-1\right) \cdot V_{\text {in }}
$$

In addition, the inductor current ripple $\Delta I_{\mathrm{L}}$ can be described as:

$$
\Delta I_{\mathrm{L}}=\frac{-u_{\mathrm{L}}}{L_{\mathrm{f}}} \cdot t_{\mathrm{f}}
$$

By substituting (7) and (8) into (9), the inductor current ripple $\Delta I_{\mathrm{L}}$ can be written as:

$$
\Delta I_{\mathrm{L}}=\frac{\left(d_{1}+d_{2}-1\right) \cdot\left(1-d_{2}\right) \cdot T \cdot V_{\text {in }}}{L_{\mathrm{f}}}
$$

When $d_{1}$ is set as $0.5, d_{2}$ is calculated as 0.75 , and $\Delta I_{\mathrm{L}_{-} \max }$ can be obtained as: 


$$
\Delta I_{\mathrm{L}_{-} \max }=\frac{V_{\text {in }} \cdot T}{16 L_{\mathrm{f}}}
$$

Therefore, the minimum value of $L_{\mathrm{f}}$ is limited by means of the required maximum inductor current ripple $\Delta I_{\mathrm{L}_{-} \max }$ :

$$
L_{\text {f_min }}=\frac{V_{\text {in }} \cdot T}{16 \Delta I_{\mathrm{L}_{-} \max }}
$$

In addition, the output voltage ripple $\Delta V_{\mathrm{o}}$ can be described as:

$$
\Delta V_{\mathrm{o}}=\frac{1}{C_{\mathrm{f}}} \times \frac{\Delta I_{\mathrm{L}}}{2} \times \frac{T}{8}=\frac{\Delta I_{\mathrm{L}} \cdot T}{16 C_{\mathrm{f}}}
$$

Hence the minimum value of $C_{\mathrm{f}}$ is described according to the inductor current ripple $\Delta I_{\mathrm{L}}$ and the required output voltage ripple $\Delta V_{\text {o_max }_{-}}$:

$$
C_{\mathrm{f}_{-} \min }=\frac{\Delta I_{\mathrm{L}} \cdot T}{16 \Delta V_{\text {o } \_ \text {max }}}
$$

As a result, the filter design of the converter can be completed theoretically by means of (12) and (14).

\section{EXPERIMENTAL RESULTS}

The proposed converter with the voltage and current double-loop control scheme, in which PI controllers are adopted has been experimentally verified. The $1 \mathrm{~kW}$ hardware prototype has been set up in the lab, as shown in Fig. 4. The experimental parameters and components are listed in Tab. 1.

Fig. 5 shows the pulse voltage $V_{\mathrm{ab}}$ (the amplitude of the pulse voltage is half the input dc voltage), the inductor current $i_{\mathrm{L}}$, and the output dc voltage $V_{\mathrm{o}}$, which is a constant $68 \mathrm{~V}$ output, and a small ripple is achieved within $\pm 2 \%$. Fig. 6 shows the waveforms of voltages across the power switches $\mathrm{Q}_{1}$ and $\mathrm{Q}_{2}$, in which the blocking voltages are also the ones across the divided capacitors $\mathrm{C}_{1}$ and $\mathrm{C}_{2}$. Therefore, the voltages of $\mathrm{C}_{1}$ and $\mathrm{C}_{2}$ are self balanced, and both of the duty cycles are around 0.45 and 0.686 , instead of $0.136(68 / 500)$. Both of these values are closer to 0.5 . Such non-extreme duty cycles are necessary for the converter when the switching frequency is increased to minimize the filter. The output three-level voltages of the half bridges $V_{\mathrm{ag}}$, and $V_{\mathrm{bg}}$ are shown in Fig. 7. They are in agreement with the theoretical analysis in Figs. 3(f) and (g).

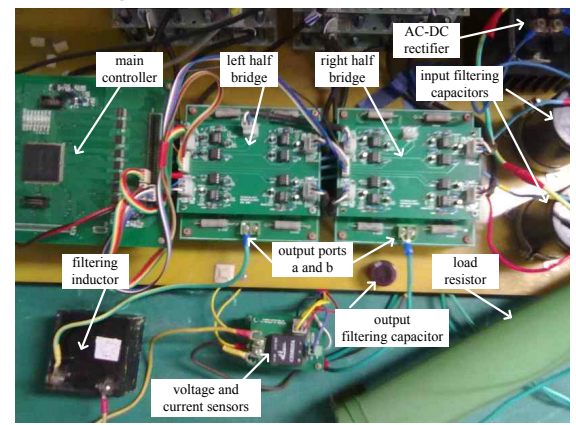

Fig. 4. 1kW hardware prototype.

\section{TABLE I}

EXPERIMENTAL PARAMETERS AND COMPONENTS

\begin{tabular}{cc}
\hline parameters and components & values (units) \\
\hline rated power $P_{\mathrm{n}}$ & $1 \mathrm{~kW}$ \\
input dc voltage $V_{\text {in }}$ & $500 \sim 640 \mathrm{~V}$ \\
reference voltage $V_{\text {ref }}$ & $68 \mathrm{~V}$ \\
input filtering capacitors $C_{1}=C_{2}$ & $2200 \mu \mathrm{F}$ \\
output filtering capacitor $C_{\mathrm{f}}$ & $160 \mu \mathrm{F}$ \\
inductor $L_{\mathrm{f}}$ & $317 \mu \mathrm{H}$ \\
switching frequency $f_{\mathrm{c}}$ & $10 \mathrm{kHz}$ and $11.36 \mathrm{kHz}$ \\
load resistor $R_{\mathrm{L}}$ & $3.8 \sim 50 \Omega$ \\
power switches $\mathrm{Q}_{1} \sim \mathrm{Q}_{4}$ & $\mathrm{FGA} 30 \mathrm{~N} 60(600 \mathrm{~V}, 30 \mathrm{~A})$ \\
diodes $\mathrm{D}_{1} \sim \mathrm{D}_{4}$ and $\mathrm{D}_{\mathrm{cl}} \sim \mathrm{D}_{\mathrm{c} 4}$ & $\mathrm{MUR} 3060(600 \mathrm{~V}, 30 \mathrm{~A})$ \\
$K_{\mathrm{pv}}$ of voltage PI controller & 10.2 \\
$K_{\text {iv }}$ of voltage $\mathrm{PI}$ controller & 1012 \\
$K_{\text {pc }}$ of current $\mathrm{PI}$ controller & 0.021 \\
$K_{\text {ic }}$ of current $\mathrm{PI}$ controller & 11.23 \\
\hline
\end{tabular}

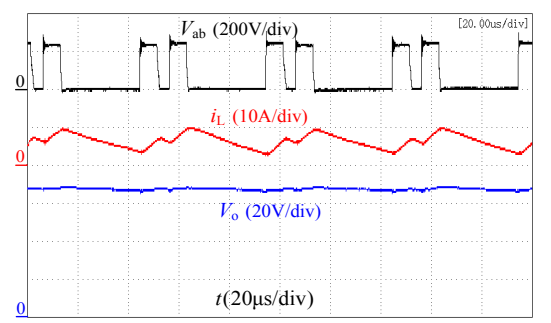

Fig. 5. Experimental waveforms of $V_{\mathrm{ab}}$ (upper), $i_{\mathrm{L}}$ (middle), and $V_{\mathrm{o}}$ (bottom), when $V_{\mathrm{in}}=500 \mathrm{~V}$ and $f_{\mathrm{c}}=10 \mathrm{kHz}$.

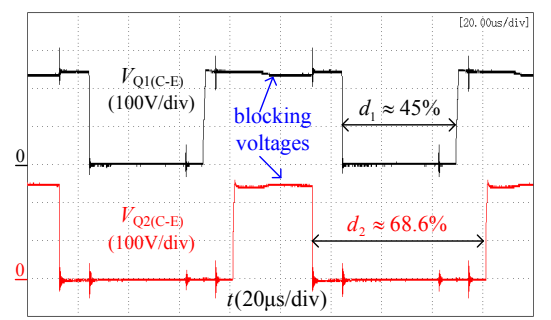

Fig. 6. Experimental waveforms of voltages across $\mathrm{Q}_{1}$ (upper) and $\mathrm{Q}_{2}$ (bottom), when $V_{\mathrm{in}}=500 \mathrm{~V}$ and $f_{\mathrm{c}}=10 \mathrm{kHz}$.

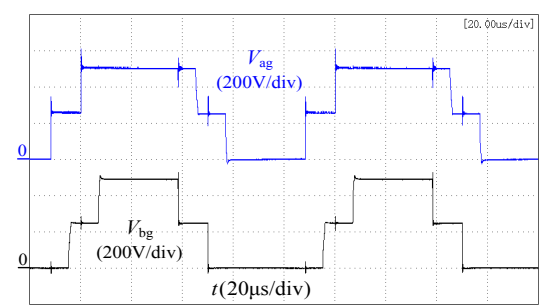

Fig. 7. Experimental waveforms of the output three-level voltages of $V_{\text {ag }}$ (upper), and $V_{\mathrm{bg}}$ (bottom), when $V_{\text {in }}=500 \mathrm{~V}$ and $f_{\mathrm{c}}=10 \mathrm{kHz}$.

Fig. 8 shows the pulse voltage $V_{\text {ab }}$ (the amplitude of the pulse voltage is still half the input dc voltage), the inductor current $i_{\mathrm{L}}$, and the output dc voltage $V_{\mathrm{o}}$ when $V_{\text {in }}$ is changed to $640 \mathrm{~V} . V_{\mathrm{o}}$ is still controlled at a constant $68 \mathrm{~V}$ output for the wide-input voltage range from $500 \mathrm{~V}$ to $640 \mathrm{~V}$, and a small ripple is still achieved within $\pm 2 \%$. 


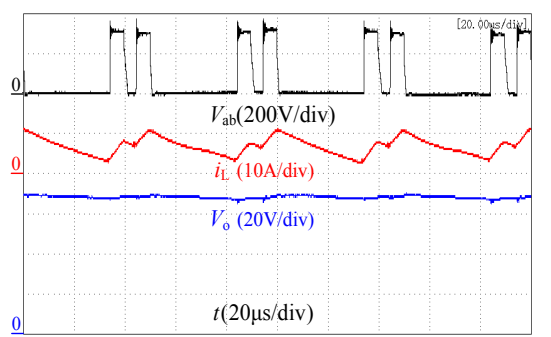

Fig. 8. Experimental waveforms of $V_{\mathrm{ab}}$ (upper), $i_{\mathrm{L}}$ (middle), and $V_{\mathrm{o}}$ (bottom), when $V_{\text {in }}=640 \mathrm{~V}$ and $f_{\mathrm{c}}=10 \mathrm{kHz}$.

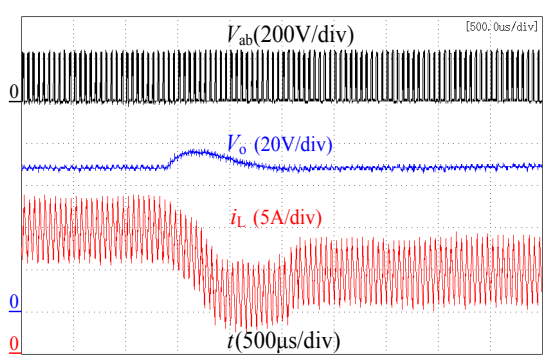

Fig. 9. Experimental waveforms of $V_{\mathrm{ab}}$ (upper), $V_{\mathrm{o}}$ (middle), and $i_{\mathrm{L}}$ (bottom), at the step load change from $4.6 \Omega$ to $7 \Omega$, when $V_{\text {in }}=500 \mathrm{~V}$ and $f_{\mathrm{c}}=10 \mathrm{kHz}$.

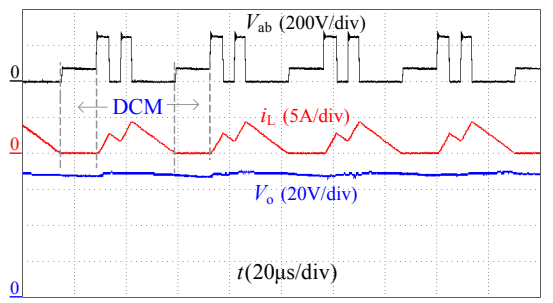

Fig. 10. DCM experimental waveforms of $V_{\mathrm{ab}}$ (upper), $i_{\mathrm{L}}$ (middle), and $V_{\mathrm{o}}$ (bottom), when $V_{\mathrm{in}}=500 \mathrm{~V}$ and $f_{\mathrm{c}}=11.36 \mathrm{kHz}$.

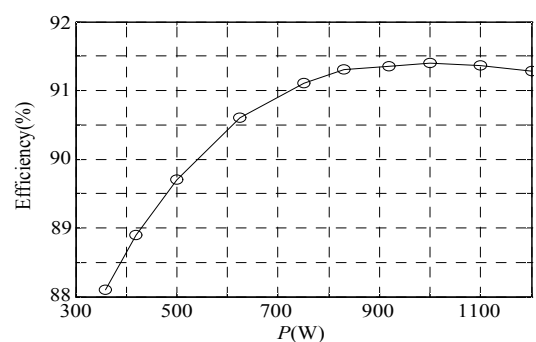

Fig. 11. Efficiency of the prototype versus output power, $V_{\text {in }}=500 \mathrm{~V}$, and $V_{\mathrm{o}}=68 \mathrm{~V}$.

The output voltages and current under step load changes are shown in Fig. 9. When the load resistor is $4.6 \Omega$, the output dc voltage $V_{\mathrm{o}}$ is around $68 \mathrm{~V}$, and the inductor current $i_{\mathrm{L}}$ fluctuates from $11 \mathrm{~A}$ to $19 \mathrm{~A}$. At the moment of the step load change (from $4.6 \Omega$ to $7 \Omega$ ), $V_{\text {o }}$ goes through the transient response, and it is still controlled at around $68 \mathrm{~V}$ after about $1 \mathrm{~ms}$, due to the voltage controller. At the same time, the inductor current $i_{\mathrm{L}}$ goes down accordingly, and then it fluctuates from $6 \mathrm{~A}$ to $14 \mathrm{~A}$ in the steady state of the conversion system. The transient response time can be reduced further by the improved controller, if the overshoot of the output dc voltage $V_{\mathrm{o}}$ and the input capacitor voltages transient balance can be considered as well.
In order to verify the usability of the proposed converter for a light load, the discontinuous conduction mode (DCM) experimental waveforms with another increased switching frequency $f_{\mathrm{c}}=11.36 \mathrm{kHz}$ are shown in Fig. 10 . The light load resistor is $45 \Omega$. Then the energy stored in the inductor is not enough to supply the load. At this point $i_{\mathrm{L}}$ becomes zero, namely it is in DCM. During DCM, the load is supplied by $C_{\mathrm{f}}$ merely, and $V_{\mathrm{ab}}$ is the voltage $V_{\mathrm{o}}$ across $C_{\mathrm{f}}$, as shown in Fig. 10. However, it is shown that $V_{\mathrm{o}}$ can still be controlled at around the reference voltage $68 \mathrm{~V}$.

When the high input de voltage $V_{\text {in }}$ is $500 \mathrm{~V}$, and the low output dc voltage $V_{\mathrm{o}}$ is controlled at $68 \mathrm{~V}$, the efficiency of the experimental prototype is measured with the output power as illustrated in Fig. 11. The maximum efficiency is approximately $91.4 \%$ under a full load. Although a lower blocking voltages across the power switches and diodes can reduce the switching losses, the soft-switching mode will improve the efficiency of the proposed converter more than the present hard-switching mode.

\section{CONCLUSIONS}

A transformerless three-level dc-dc buck converter with a high step-down conversion ratio is proposed. Such a converter can operate over a wide input voltage range for high voltage applications with fewer low-voltage-rated power components. It can also avoid extreme duty cycles without a transformer. The voltages across the two series capacitors are self balanced with the proposed modulation strategy, the blocking voltages of the IGBTs are half the input dc voltage, and the equivalent frequency of the output pulse voltage is double the switching frequency. From the experimental results, it can be seen that such a dc-dc converter displays good performance and hence is suitable for high power converters operating from a high-input dc voltage to a low-output de voltage. It would be especially useful for ship electric power distribution systems.

\section{ACKNOWLEDGMENT}

This work was supported in part by the Special Scientific and Research Funds for Doctoral Speciality of Chinese Institution of Higher Learning under Grant 20110032120082, and in part by the National Natural Science Foundation of China under Grant 51207104.

\section{REFERENCES}

[1] H. M. Pirouzy and M. T. Bina, "Modular multilevel converter based STATCOM topology suitable for medium-voltage unbalanced systems," Journal of Power Electronics, Vol. 10, No. 5, pp. 572-578, Sep. 2010.

[2] E. Babaei, "Optimal topologies for cascaded sub-multilevel converters," Journal of Power Electronics, 
Vol. 10, No. 3, pp. 251-261, May 2010.

[3] F. Iturriz and P. Ladoux, "Phase-controlled multilevel converters based on dual structure associations," IEEE Trans. Power Electron., Vol. 15, No. 1, pp. 92-102, Jan. 2000.

[4] H. Mohammadi and M. T. Bina, "A transformerless medium-voltage STATCOM topology based on extended modular multilevel converters," IEEE Trans. Power Electron., Vol. 26, No. 5, pp. 1534-1545, May 2011.

[5] M. L. Heldwein, S. A. Mussa, and I. Barbi, "Three-phase multilevel PWM rectifiers based on conventional bidirectional converters," IEEE Trans. Power Electron., Vol. 25, No. 3, pp. 545-549, Mar. 2010.

[6] M. Hagiwara and H. Akagi, "Control and experiment of pulsewidth-modulated modular multilevel converters," IEEE Trans. Power Electron., Vol. 24, No. 7, pp. 1737-1746, Jul. 2009.

[7] K. Hasegawa and H. Akagi, "A new DC-voltage-balancing circuit including a single coupled inductor for a five-level diode-clamped PWM inverter," IEEE Trans. Ind. Appl., Vol. 47, No. 2, pp. 841-852, Mar./Apr. 2011.

[8] Y. Zhang and L. Sun, "An efficient control strategy for a five-level inverter comprising flying-capacitor asymmetric h-bridge," IEEE Trans. Ind. Electron., Vol. 58, No. 9, pp. 4000-4009, Sep. 2011.

[9] Z. Du, L. M. Tolbert, B. Ozpineci, and J. N. Chiasson, "Fundamental frequency switching strategies of a seven-level hybrid cascaded H-bridge multilevel inverter," IEEE Trans. Power Electron., Vol. 24, No. 1, pp. 25-33, Jan. 2009.

[10] A. Nabae, I. Takahashi, and H. Akagi, "A new neutral-point-clamped PWM inverter," IEEE Trans. Ind. Appl., Vol. 1A-17, No. 5, pp. 518-523, Sep./Oct. 1981.

[11] J. R. Pinheiro and I. Barbi, "The three-level ZVS PWM converter a new concept in high-voltage dc-to-dc conversion," in Conf. Rec. IECON, pp. 173-178, 1992.

[12] X. Ruan, B. Li, Q. Chen, S. C. Tan, and C. K. Tse, "Fundamental considerations of three-level dc-dc converters: topologies, analyses, and control," IEEE Trans. Circuits Syst. I, Reg. Papers, Vol. 55, No. 11, pp. 3733-3743, Dec. 2008.

[13] B. Axelrod, Y. Berkovich, and A. Ioinovici, "Switched-capacitor/switched-inductor structures for getting transformerless hybrid dc-dc PWM converters," IEEE Trans. Circuits Syst. I, Reg. Papers, Vol. 55, No. 2, pp. 687-696, Mar. 2008.

[14] E. H. Ismail, M. A. Al-Saffar, and A. J. Sabzali, "High conversion ratio dc-dc converters with reduced switch stress," IEEE Trans. Circuits Syst. I, Reg. Papers, Vol. 55, No. 7, pp. 2139-2151, Aug. 2008.

[15] L. Huber and M. M. Jovanovic, "A design approach for server power supplies for networking applications," in Conf. Rec. IEEE APEC, pp. 1163-1169, 2000.

[16] B. M. Song, R. McDowell, A. Bushnell, and J. Ennis, "A three-level dc-dc converter with wide-input voltage operations for ship-electric-power-distribution systems," IEEE Trans. Plasma Sci., Vol. 32, No. 5, pp. 1856-1863, Oct. 2004.

[17] V. F. Pires and J. F. Silva, "Single-stage double-buck topologies with high power factor," Journal of Power Electronics, Vol. 11, No. 5, pp. 655-661, Sep. 2011.

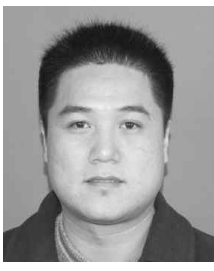

Yun Zhang was born in Jiangsu, China, in 1980. He received his B.S. and M.S. in Electrical Engineering from the Harbin University of Science and Technology, Harbin, China, in 2003 and 2006, respectively, and his Ph.D. in Electrical Engineering from the Harbin Institute of Technology, Harbin, China, in 2010. Since 2010 he has been a member of the teaching and research staff in the School of Electrical Engineering and Automation, Tianjin University, Tianjin, China. His current research interests include power conversion systems and controls, power electronics technique applied to distributed generation systems, and motor control. Dr. Zhang is a Member of the Chinese Society for Electrical Engineering and is also a Member of IEEE.

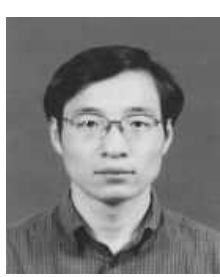

Xing-tao Sun was born in Heilongiiang, China, in 1974. He received his B.S. in Electrical Engineering from Wuhan University, Wuhan, China, in 1997, and his M.S. and Ph.D. in Electrical Engineering from the Harbin Institute of Technology, Harbin, China, in 2003 and 2009, respectively. He is currently a Lecturer in the School of Electrical Engineering and Automation, Tianjin Polytechnic University, Tianjin, China. His current research interests include multilevel power conversion and motor control.

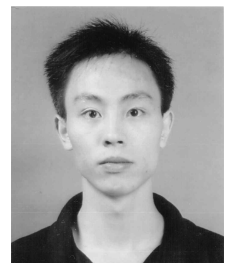

Yi-feng Wang was born in Hubei, China, in 1981. He received his B.S., M.S. and Ph.D. all in Electrical Engineering from the Harbin Institute of Technology, Harbin, China, in 2005, 2007 and 2011, respectively. He is currently a Lecturer in the School of Electrical Engineering and Automation, Tianjin University, Tianjin, China. His current research interests include grid connected inverters applied in renewable energy systems, special power supplies, and electronic lighting.

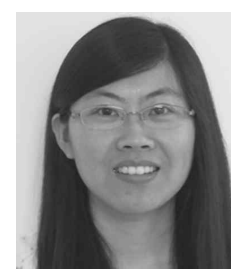

Hong-jun Shao was born in Liaoning, China, in 1983. She received her B.S. from Tianjin Polytechnic University, Tianjin, China, in 2005 and her M.S. from Tianjin University, Tianjin, China, in 2009, respectively, all in Electrical Engineering. She is currently working towards her Ph.D. in Electrical Engineering in the School of Electrical Engineering and Automation, Tianjin University, Tianjin, China. Her current research interests include multilevel power conversion and motor control. 